\title{
Copyright Protection and Role of Publishers: Perceptions of Indian Authors
}

\author{
PK Madhavan, K Sundar
}

\begin{abstract}
Copyright laws provide the legal framework to the business of publishing, and authors and publishers have benefitted enormously over the last 100 years or more from the existing copyright regime.

The objective of copyright law is to reward the creativity of authors while ensuring that the general public has access to the creativity and innovation of authors. Publishers invest in the content and intellectual property rights assigned to them by authors. What provides value to their investment is the protection provided by copyright laws to the seamless acquisition and transfer of the intellectual property asset. This paper, the first of its kind on authors and copyright in India, focuses on Indian author perceptions on the role of publishers in protecting copyright.
\end{abstract}

Keywords: Copyright, Digital Copyright, IPR, Freedom of Expression, Subsidiary Rights, Statute of Anne , Self-Publishing, Digital Era.

\section{INTRODUCTION}

Historically, (that is immediately after the invention of the printing press) copyright laws protected printers, booksellers and entrepreneurs in the domain first (later christened publishers) before protecting the interests of authors.[1] The Statute of Anne in 1709, was the first 'recognised' copyright law in the world. It provided authors with exclusive rights to print copies of their unprinted works for a period of 14 years, established a system of penalty for infringement, and accorded sole ownership and rights of printing to authors after the period of 14 years, and further extension by 14 years if the author was living. It also introduced a system of registration of titles to be eligible for copyright protection.[2]

The industrial era, the rise of democratic nation states, the developmental impact of science and the contribution of authors and innovators to society along with the role played by authors and publishers in enriching cultural and social life, led to authors and publishers assuming centre stage in intellectual property discussions.[3]

In India, under the British regime, the earliest statutory law on copyright was the Indian Copyright Act 1847, followed by the Copyright Act of 1911, and the Copyright Act 1914 which was in force till the enactment of the Indian Copyright Act 1957.[4]

The basis of legal protection to authors was a recognition of author 'interests' in their works. The skill,

Revised Manuscript Received on October 15, 2019.

PK Madhavan: Department of Management Studies, SCSVMV University,Kancheepuram, Tamil Nadu, India

K Sundar: Department of Commerce, Annamalai University, Chidambaram, Tamil Nadu, India creativity, idea, labour, effort, time spent, ability and genius of authors were perceived worthy of legal protection. Copyright law recognised the interests of author to be economic as well as moral.[5]

The focus of this paper is on the impact of the copyright system on the creative process of writing, and the perceptions of Indian authors on the role played by publishers in protecting their copyright. In ancient cultures and in India too, all knowledge was considered free. Paul Gleeson (1995) says that to understand the roots of copyright, "works of the mind did not belong to individuals or groups that created them but to the community and the larger society".[6] Michael Bhaskar (2014) arguing along the same lines says, "that for much of history many works, like epic poems, didn't require an author at all, they were part of a shared heritage. Then in the seventeenth and eighteenth centuries it became more common to ask, 'who wrote it'?'[7]

As such, it is pertinent to ask if copyright is a consideration for authors in their process of writing. Cantatore (2011) is emphatic that copyright is not an incentive to create and is not significant during the creative process of writing. She says authors would create no matter what and do not think of copyright while writing and at least till they are ready to submit their scripts to publishers.[8] In many instances, this researcher in his 30 years of experience with authors has observed that authors wait for publishers to tell them about copyright and some sign their publishing contracts without even reading them.

Nevertheless, it is important to ask if authors are influential enough to tackle issues that affect them be it on copyright issues, freedom of expression, or digital copyright challenges. In the famous Google vsAuthors Guild, (2005) publishers and authors teamed up to present a united front.[9]

In freedom of expression cases pertaining to the author PerumalMurugan's "One Part Woman" and the author Hareesh's "Meesha", Federation of Indian Publishers and the publishers of the books put up a united battle in the courts and won.[10]

Reddy and Chandrasekaran (2017) argue that the parliamentarians post-independence were authors, writers, editors, poets, journalists and men of letters who were all very influential in protecting their interests. Rama Rao, Ramdhari Singh Dinkar, MinooMasani, WS Barlingay were all authors who supported stricter copyright laws and ratification of the Berne Convention during the period when the official Indian stand was to get educational material exempt from stringent copyright requirements. Likewise, the copyright law on translations was introduced in 
1895 as the English publishers OUP, CUP and Macmillan (publishers of Rabindranath Tagore) found the translation market in India attractive and lobbied for translation rights and got it enacted in the copyright act of 1914-" "publishers justified their demand for expanding copyright law to include translation rights, but masked it as being needed to protect the interest of authors. Macmillan cited the example of theIndian poet and author Rabindranath Tagore, who had around the time been awarded the Nobel Prize for Literature (1913) to defend their demand. Macmillan argued that lack of such rights would adversely affect Tagore, whose translated works were in great demand in Europe and elsewhere".

In the framing of copyright legislation, Indian authors have been and continue to be powerful and influential.[11]However, VinuthaMallaya says, the authors guild in India once a powerful body is now defunct.

Authors and publishers have benefitted enormously over the last 100 years or more from the existing copyright regime. In the digital era, the greatest impact of digital disruption is on the edifice of copyright. The Internet technologies shake the very foundations of copyright the most, and digital challenges to copyright have assumed centre stage in discussions on publishing. One of the offshoots of digital publishing is self-publishing by authors wanting to retain control over copyright and the various others processes of publishing.

In this milieu, the research questions asked of author respondents were as follows:

1. Do authors think of copyright after completing their draft script and before submitting it to the publishers?

2. Do authors wait for publishers to help/guide them about copyright?

3. Do authors rely on publishers to protect their copyright?

4. Do publishers educate authors about copyright and its implications?

5. Do publishers inform and educate authors about subsidiary rights (translation, territory, media, broadcast rights, etc.)

6. How do authors perceive the criticality ofthe copyright protection role of publishers?

\section{REVIEW OF LITERATURE}

Paul Gleeson (1995) says that in ancient cultures, works of the mind did not belong to the individuals or groups who created them but to the community and larger society with writers and other artists commonly perceived as expressing the collective consciousness of the community. Quoting Ithiel de Sola Pool, he says printing technology changed the game as it was easier to control the press, as the logical place to apply controls (to prevent sedition, sacrilege or protect the author's intellectual property, etc.) from the author's pen to the reader's hand.

John Thompson(2005) narrates the thin differences between early printers and publishers and emphasises the role of the modern publisher as an investor and risk taker, with copyright providing protection to their investment.[12] $\mathrm{He}$ says publishers acquire rights in symbolic content and hope to sell the physical product in adequate numbers to recover investments and make a profit. He avers that the impact of the digital revolution on publishing is profound and irreversible and that digitization affects the operations, process and content management, marketing and service and content delivery. But he feels the biggest impact is that of the realisation by publishers that they possess digital assets that can be manipulated and stored in digital ways.

Matias Vaara(2010) describes traditional book publishers as being too reliant on a few hits to offset and make up for the losses suffered by others in a 1:10 ratio where 1 title is a hit, 3 are break-even and 6 are loss-makers.[13] Quoting Tapaninen, a Finnish Publisher, he says that the core competence of publishers is finding and nurturing talent or find authors who can deliver winning content to the audience catered to by the publisher - the job of a publisher being that of a portfolio manager. Publishers play the role of gatekeepers in the analogue environment, wherein content creation belongs to an elite club of authors, agents and editors. Vaara says in digital publishing, the concept is publish-first and filter-later or the process of filtering happens as a process of natural selection or Darwinian evolution. The pitfall in all this is the specialisation and carefully cultivated domain knowledge and mastery of publishers is replaced with mass amateurisation in digital publishing.

Cantatore (2011) studies the habits of Australian authors in the process of writing. She asks author respondents whether they thought about copyright before writing, while writing or after writing and their interaction with publishers and their dependence on publishers to educate and inform them about issues pertinent to copyright. She is emphatic that authors seldom think of copyright in the process of writing and copyright is not a motivating factor at all in their writing process. She alsoasserts that most Australian authors are dependent on their publishers for information regardingvarious copyright aspects. She says that a whopping $73 \%$ of authors experienced satisfactory relationships with publishers and most of them were dependent on publishers to educate them on copyright and could not assert themselves on copyright issues and in their contractual obligations or MOAs with publishers.

Kevin Smith(2012) feels the role of publishers and publishing professionals have been challenged but revolve around authorship, content processing, content delivery, financial models and legal structures.[14]

Frania Hall(2013) says the publishing value chain must be reconfigured to suit the digital workflow, to integrate aspects of digital marketing and social media, and to facilitate asset management in order to cater to requirements of granularity like chapters, spin-offs, versions and snippets.[15]She feels publishers must structure themselves to provide customers direct access to quality content, reduce time to market, be flexible and provide easy access in production, adopt just in time and print on demand distribution strategies, think global and offer products on sale in multiple formats offline and online and build relationships suitable for the digital environment.

Giles Clark and Angus Philips(2014) in describing what publishers do outline the many roles played by publishers including that of identifying and selecting topics and areas to publish, commissioning authors, value-adding to the 
content provided by authors, financing the production and marketing of the work, committing resources in terms of sales personnel, promotional activities, advertisement, public relations, organising events, participating in fairs and exhibitions, etc. and protecting copyright.[16]

Michael Fraser(2016) in his speech 'What are Publishers for', says, "Publishers have been revered for three centuries as champions and gatekeepers of culture and learning, and arbiters in quality and taste in writing".[17] He is emphatic that publishers protect the value of copyright for authors and as producers of content the value of their investment. He opines that publishers play a vital role in upholding freedom of speech and the fundamental principle of human right. $\mathrm{He}$ articulates that a fair marketplace for ideas and content is important for culture, art and innovation and is the bedrock of democratic society as opposed to a system of patronage and sponsorship and authoritarianism.

He exhorts publishers to pursue advocacy for copyright, establish proprietary centrally management licensing systems, set standards for minimum royalties for authors, and continue to be vigilant about online intermediaries and the like and ensure reasonable responsibility from them.

Ravi Singh(2017) underscores the crucial importance of establishing strong relationships of mutual trust with authors.[18]He says the role of the publisher is working closely with authors especially authors who are loyal to the publishing firm and build an identity and brand for the author and the company. In addition, he feels, once a decision to publish has been taken, the publisher must defend the book and the author and be prepared to commit resources in terms of time, effort and legal expenses.

\section{OBJECTIVES OF THE STUDY}

1. To analyse the influence of the copyright system on the creative process of writing.

2. To study the role and importance of publishers in protecting copyright.

3. To understand author perceptions on the role of implications and subsidiary rights.

\section{RESEARCH METHODOLOGY}

\begin{tabular}{|c|c|}
\hline Research Design & Descriptive Research Design \\
\hline Data Source & Primary and Secondary \\
\hline Questionnaire & Structured questionnaire \\
\hline Period of Study & January 2018 - March 2018 \\
\hline Population & $\begin{array}{l}\text { Authors of } \\
\text { origin/estimated } \\
\text { authors }\end{array}$ \\
\hline Sample size & 408 author respondents \\
\hline $\begin{array}{l}\text { Sampling } \\
\text { methodology }\end{array}$ & $\begin{array}{l}\text { A mix of random, stratified } \\
\text { random and convenience } \\
\text { sampling from universities, } \\
\text { colleges, professionals, social } \\
\text { media platforms and all allied } \\
\text { networks. }\end{array}$ \\
\hline
\end{tabular}
publishers in educating authors about copyright

\begin{tabular}{|l|l|}
\hline Data Collection & $\begin{array}{l}\text { Direct one to one interview of } \\
50 \text { authors email and } \\
\text { hardcopy collection of } \\
\text { questionnaires, collecting } \\
\text { responses from professionals, } \\
\text { social media contacts and their } \\
\text { networks. }\end{array}$ \\
\hline Types of analysis & $\begin{array}{l}\text { Statistical tools used includes } \\
\text { percentage analysis, Friedman } \\
\text { test, Kruskal-Wallis test, } \\
\text { Chi-square test, T-test, } \\
\text { Correlation, ANOVA and } \\
\text { multiple regression. }\end{array}$ \\
\hline
\end{tabular}

\section{Data Interpretation and Analysis}

Table 1 Influence of the copyright system on the creative process of writing

\begin{tabular}{|c|c|c|c|c|c|c|c|c|}
\hline Motivational factors & Always & Often & Sometime & Rarek & Never & Total & Mean & SD \\
\hline $\begin{array}{l}\text { Author Familiarity } \\
\text { withCopyright }\end{array}$ & $\begin{array}{c}87 \\
(21.3)\end{array}$ & $\begin{array}{c}157 \\
(38.5)\end{array}$ & $\begin{array}{c}29 \\
(7.1)\end{array}$ & $\begin{array}{c}118 \\
(28.9) \\
\end{array}$ & $\begin{array}{c}17 \\
(4.2)\end{array}$ & $\begin{array}{c}408 \\
(100.0)\end{array}$ & 3.43 & 1.22 \\
\hline $\begin{array}{l}\text { Authors think of Copyright } \\
\text { after completing the Draft } \\
\text { script and before Submitting } \\
\text { to Publisher }\end{array}$ & $\begin{array}{c}96 \\
(23.5)\end{array}$ & $\begin{array}{c}153 \\
(37.5)\end{array}$ & $\begin{array}{c}71 \\
(17.4)\end{array}$ & $\begin{array}{c}32 \\
(7.8)\end{array}$ & $\begin{array}{c}56 \\
(13.7)\end{array}$ & $\begin{array}{c}408 \\
(100.0)\end{array}$ & 3.49 & 1.30 \\
\hline $\begin{array}{l}\text { Authors expect publishers to } \\
\text { guide them about copyright }\end{array}$ & $\begin{array}{c}50 \\
(12.3)\end{array}$ & $\begin{array}{c}109 \\
(26.7)\end{array}$ & $\begin{array}{c}85 \\
(20.8)\end{array}$ & $\begin{array}{c}54 \\
(13.2)\end{array}$ & $\begin{array}{c}110 \\
(27.0)\end{array}$ & $\begin{array}{c}408 \\
(100.0)\end{array}$ & 2.84 & 1.39 \\
\hline
\end{tabular}

Table 1 sought answers from Indian authors on various aspects of their thought process on copyright including their familiarity with copyright; on when they thought about copyright, before, during or after completing their draft script and or before they submitted their scripts to publishers; and or do they seek help from publishers, agents or editors to guide them on copyright issues.

It is clear from table 1 that $60 \%$ of author respondents are familiar about copyright. About $7 \%$ are neutral while $33 \%$ are not familiar with copyright laws. The mean score of 3.43 indicates that amoderately high number of author respondents are familiar with copyright. But it is quite revealing that about $33 \%$ of authors are not familiar with the copyright system.

On the question of when do authors think about copyright, it is evident from the responses received from authors in this survey that $61 \%$ of the authors (249/408) think about copyright after completing their draft script and before submitting the same to publishers. About $17 \%$ are neutral and $22 \%$ have negated this. A mean score of 3.49 indicates a moderately high acceptance of authors thinking of copyright only after completing their script and prior to submission to publishers.

As to the question of, "I wait for my publisher/editor to help/guide me about copyright", 159 (39\%) of the respondents depend on their publishers to inform them about copyright. Authors numbering 164 constituting 40\% of authors surveyed do not expect their publishers to guide them about copyright issues.

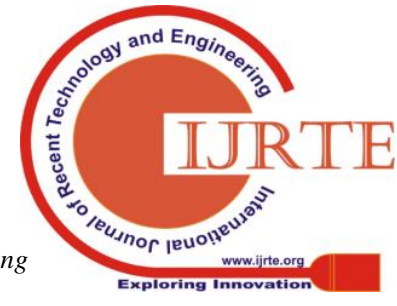


A mean score of 2.34 validates the fact that only $39 \%$ of the authors expect help from publishers on copyright issues.

Table 2 Copyright protection and the role of publishers

\begin{tabular}{|c|c|c|c|c|c|c|c|c|}
\hline Role of Publishers & Always & Often & $\begin{array}{l}\text { Some } \\
\text { times }\end{array}$ & Rarely & Never & Total & Mean & SD \\
\hline $\begin{array}{l}\text { Author reliance on publishers to } \\
\text { protect copyright }\end{array}$ & $\begin{array}{l}214 \\
(52.5)\end{array}$ & $\begin{array}{l}100 \\
(24.5)\end{array}$ & \begin{tabular}{l|l}
46 \\
$(11.3)$
\end{tabular} & $20(4.9)$ & $28(6.9)$ & $\begin{array}{l}408 \\
(100.0)\end{array}$ & 4.10 & 1.20 \\
\hline $\begin{array}{l}\text { Publishers educate authors about } \\
\text { copyright and its implications }\end{array}$ & $\begin{array}{l}93 \\
(22.8)\end{array}$ & $\begin{array}{l}91 \\
(22.3)\end{array}$ & $\left|\begin{array}{l}124 \\
(30.4)\end{array}\right|$ & $\begin{array}{l}46 \\
(11.3)\end{array}$ & $\begin{array}{l}54 \\
(13.2)\end{array}$ & $\begin{array}{l}408 \\
(100.0)\end{array}$ & 3.30 & 1.30 \\
\hline $\begin{array}{l}\text { Publishers inform authors of } \\
\text { various subsidiary rights } \\
\text { (Translation/territory/media/ } \\
\text { broadcast rights) }\end{array}$ & $\begin{array}{l}63 \\
(15.4)\end{array}$ & $\begin{array}{l}93 \\
(22.8)\end{array}$ & $\begin{array}{l}126 \\
(30.9)\end{array}$ & $\begin{array}{l}59 \\
(14.5)\end{array}$ & $\begin{array}{l}67 \\
(16.4)\end{array}$ & $\begin{array}{l}408 \\
(100.0)\end{array}$ & 3.06 & 1.28 \\
\hline
\end{tabular}

Table 2 deals with copyright protection and the role of publishers. In a set of three questions, authors were asked on how much they rely on publishers to protect their copyright, whether publishers educate them about copyright and its implications and whether they (authors) are made aware of subsidiary rights including translation, territory and media and allied rights by their publishers.

As many as $314 / 408$ constituting $77 \%$ of authors opined that they were totally reliant on publishers to protect their copyright. Only 48 authors (12\%)indicated that they were not reliant on publishers to protect their copyright. The mean score of 4.10 is surely indicative of the reliance of authors on publishers to protect their copyright.

As to the question of whether publishers educate authors on copyright and its implications, only 184 (45\%) authors received instructions and education on the topic. About 100 authors did not receive any help or education on copyright from their publishers and 124 authors were neutral to the idea of receiving help from their publishers on the important issue of copyright education.

On subsidiary rights, 156 authors respondents $(38 \%)$ received instruction and information about subsidiary rights from publishers while $31 \%$ did not and the balance $31 \%$ were neutral. In all, the mean scores of 3.30 and 3.06 point to the moderate support provided by publishers to authors about copyright education and subsidiary rights respectively.

Table 3 Criticality of the protector of copyright role of publishers

\begin{tabular}{|c|c|c|c|c|c|c|c|c|}
\hline Role of publishers & Always & Often & Sometimes & Rarely & Nevel & Total & Mean & SD \\
\hline Protector of copyrightrole & $221(54.2)$ & 135 & 35 & 13 & 4 & 408 & & \\
& & $(33.1)$ & $(8.6)$ & $(3.2)$ & $(1.0)$ & $(100.0)$ & 4.36 & .84 \\
\hline
\end{tabular}

Publishers play many roles including financing, marketing, gatekeeping and selection of content, motivating authors, value-adding to content etc. Of all these roles,the protector of copyright role was endorsed by a whopping 356 authors out of the 408 respondents constituting $87 \%$. This role had a mean score of 4.36 indicating a very high acceptance amongst authors for the role of protector of copyright.

\section{SUMMARY OF FINDINGS}

1. It is abundantly evident from the study that for Indian authors, copyright issues are not part of their thought structure till the completion of their writing and creative processes. As such, the copyright system does not influence the creative process of writing.

2. Indian authors are moderately familiar about copyright, think of copyright only after completing their writing process and prior to submission to publishers.

3. Nearly $40 \%$ of Indian authors do not expect and wait for publishers to guide them about copyright while $39 \%$ of author respondents do wait for their publishers to inform them of copyright issues. As such authors do expect guidance from publishers on copyright issues.

4. A majority of $77 \%$ author respondents in the survey were totally reliant on publishers to protect their copyright.

5. While authors expect guidance, information and instructions on copyright and its implications, only $45 \%$ of authors felt that they received such help from publishers.

About

25 percent were emphatic that they did not receive instructions and help from publishers while 30 percent of the authors were neutral, unaware or non-committal to the idea of getting help on copyright issues from publishers.

6. As regards subsidiary rights, only 38 percent of authors in the survey received help and instructions on subsidiary rights. About 31 percent were neutral and the balance 31 percent did not receive instructions or guidance on subsidiary rights.

7. On the criticality of the role of publishers, a big 87 percent of the respondents felt that of all the roles played by publishers, the protector of copyright role was the most critical.

\section{RESEARCH BASED SUGGESTIONS}

1. In order to tackle issues affecting authors such as on copyright, digital copyright and freedom of expression it is pertinent that authors network and help each other by forming guilds or being part of author/writer organisations etc.

2. It is equally important for publishers to understand that they have a symbiotic relationship with authors and guide and educate authors on all copyright issues.

3. In the wake of the proliferation of self-publishing, it is clear from the survey that authors who sign up with traditional publishers expect publishers to don the mantle of protector of copyright role and look after author interests proactively.

\section{CONCLUSION}

Publishers invest in the intellectual property assigned to them by authors. As is clear from this paper, authors especially in the traditional publishing milieu consider the protector of copyright role of publishers the most valuable. However for authors, copyright is not a consideration during the creative process of their writing. Authors think of copyright prior to getting published. They expect publishers to educate and inform them of copyright implications, and subsidiary rights. Authors and publishers have a symbiotic relationship and need to strengthen their relationships in order to tackle issues of freedom of expression, copyright per se and digital

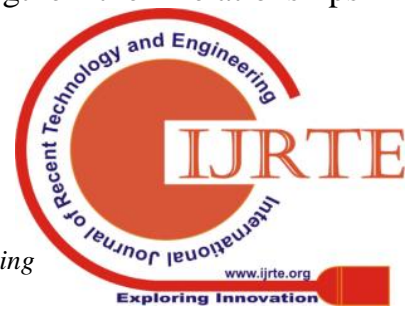


copyright. But authors have a distinct contractual agreement with publishers and need to protect themselves in their relationships with publishers. Authors will need to form networks and be part of writer and author organisations to protect their interests. Publishers will do well to be transparent and inform and educate authors on all issues pertaining to copyright and subsidiary rights. The era of digital publishing will see more cases of copyright violations and both authors and publishers will have to work together to protect their interests.

\section{REFERENCES}

1. Bhaskar, Michael, The Content Machine, 2013, The Anthem Press, London

2. Ahuja, VK, Law of Copyright and Neighbouring Rights, National and International Perspectives, 2015, Lexis Nexis, Gurgaon, India

3. Menell, Peter S, Intellectual Property: General Theories, 1999, https://reference.findlaw.com/lawandeconomics/1600-intellectual-proper ty-general-theories.pdf

4. Ahuja, VK, Law of Copyright and Neighbouring Rights, National and International Perspectives, 2015, Lexis Nexis, Gurgaon, India

5. Chawla, Alka, Law of Copyright: Comparative Perspectives, 2013, Lexis Nexis, Gurgaon, India

6. Gleeson, Paul, International Copyright, 1995, Altbach and Hoshino, International Book Publishing: An Encyclopaedia, Fitzroy Dearborn Publishers, London \& Chicago

7. Bhaskar, Michael, The Content Machine, 2013, The Anthem Press, London

8. Cantatore, Francina C, Negotiating a Changing Landscape: Authors, Copyright and Digital Evolution, 2010, Bond University, (accessed in 2015)

9. Mahalwar, Vandana, Copyright and Human Rights: The Quest for a Fair Balance, (pg 171), Sinha and Mahalwar, Editors, Copyright Law in the Digital World, 2017, Springer, New Delhi

10. Mallya, Vinutha, Numbers and Letters: The Possibilities and Pitfalls before India's Publishing Industry, 2016, The Caravan Magazine

11. Reddy, Prasant T and ChandrasekaranSumathi, Create, Copy, Disrupt, India's Intellectual Property Dilemmas, 2017, OUP, New Delhi

12. Thompson, John B, Books in the Digital Age, 1995, Polity Press, Cambridge

13. Vaara, Matias, Digital Disruption faced by the Book Publishing Industry, 2010, Tampere University, (Accessed from the web in 2016)

14. Smith, Kevin, The Publishing Business: From p-books to e-books, 2012, Ava Books, Switzerland

15. Hall, Frania, The Business of Digital Publishing, 2013, Anthem Press, London

16. Clark, Giles \&Philps, Angus, Inside Book Publishing 5E, 2014, Routledge, London New York

17. Fraser, Michael, What are Publishers for?2016, Logos, 27/3

18. Singh, Ravi, The Author-Publisher Relationship, Editor DevasarNitasha, Publishers on Publishing, AAP, New Delhi. 